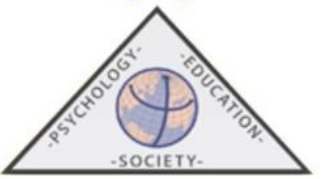

\title{
A preliminary study on the application of Behavioral Activation in the treatment of smoking in women
}

\author{
Johanna Gabriela Sánchez Angulo ${ }^{1}$, Jorge Barraca Mairal², José Rogelio Pérez Padilla ${ }^{3}$, Ireri \\ Isadora Thirion ${ }^{3}$, Jazmín Mora Ríos ${ }^{4}$, Sara E. Cruz Morales ${ }^{1}$, Leonor García Gómez ${ }^{3}$ \\ ${ }^{1}$ Universidad Nacional Autónoma de México \\ ${ }^{2}$ Universidad Camilo José Cela (España) \\ ${ }^{3}$ Instituto Nacional de Enfermedades Respiratorias (México) \\ ${ }^{4}$ Instituto Nacional de Psiquiatría Ramón de la Fuente Muñiz (México) \\ Recibido el 15 de mayo de 2020. Aceptado el 30 de diciembre de 2020
}

\begin{abstract}
The present study evaluated the effectiveness of Behavioral Activation (BA) on women smokers with depression and anxiety symptoms who received multi-component treatment for smoking cessation. Forty-nine women were randomly assigned to two groups. 1) experimental: BA and varenicline and 2) control, cognitive behavioral therapy for smoking cessation and varenicline. Both treatments were applied in 10 twice-weekly. The Beck Depression Inventory II, the Beck Anxiety Inventory, the Fasgeström Test, Smokerlyzer® piCO monitor for carbon monoxide breath tests, and the Behavioral Activation Scale for Depression were used. Project-by-Project Analysis (PPA) was carried out with bivariate logistic regression, including only those who had completed the treatment and follow-ups. In the second, Intention-to-Treat Analysis (ITA) used the Kaplan-Meier non-parametric method and the Log Rank Test for all those initially randomized. The results showed that the abstinence rate with the BA treatment was higher than for the cognitive behavioral treatment for smoking cessation. Furthermore, BA loss was lower than with the standard treatment. We therefore conclude that BA + varenicline was effective from the end of the smoking cessation treatment to the six-month follow-up.
\end{abstract}

Keywords: multicomponent intervention; varenicline, behavioral activation; smoking, comorbidity.

\section{Un estudio preliminar sobre la aplicación de la activación conductual en el tratamiento del tabaquismo en mujeres.}

RESUMEN: El presente estudio evaluó la efectividad de la activación conducta (AC) sobre el consumo de tabaco en mujeres con síntomas de depresión y ansiedad que recibieron tratamiento multi-componente para dejar de fumar. Participaron 49 mujeres asignadas aleatoriamente a dos grupos: 1) experimental, tratamiento de AC y vareniclina y 2) control, tratamiento cognitivo conductual para dejar de fumar y vareniclina. Ambos tratamientos se aplicaron durante 10 sesiones. Se usó el Inventario de Depresión de Beck-II, Inventario de Ansiedad de Beck, el Test de Fasgeström, el dispositivo marca Smokerlyzer, modelo piCO simple para medir cooximetría exhalada, y la Escala de Activación Conductual para la Depresión. Se analizaron los datos a través de dos métodos. En el primero se utilizó el Análisis Por Proyecto (APP) a través de la Regresión Logística Bivariada, incluyendo solamente a quienes habían culminado el tratamiento y los seguimientos a seis meses. En el segundo método, se usó el Análisis por Intención a Tratar (AIT) utilizando el procedimiento no paramétrico de Kaplan Meier y el Test de Log Rank con todos los que se aleatorizaron inicialmente para el estudio. Los resultados arrojaron que la proporción de abstinencia del tratamiento de AC es superior al tratamiento cognitivo conductual para dejar de fumar. Finalmente, la pérdida de participantes en el grupo de AC fue menor en comparación al tratamiento estándar. Por lo que se concluyó que el grupo que recibió AC y vareniclina, mostró ser efectivo desde el final del tratamiento para dejar de fumar hasta el seguimiento a seis meses.

Palabras clave: intervención multicomponente, vareniclina, activación conductual, tabaquismo, comorbilidad.

Correspondencia: Jorge Barraca Mairal. Universidad Camilo José Cela C/ Castillo de Alarcón, 49 -Urb. Villafranca del Castillo-28692 Madrid. jbarraca@ucjc.edu 


\section{Introduction}

According to the World Health Organization (WHO, 2019), tobacco use and exposure to smoke are major worldwide public health problems, and one of the main modifiable risks associated with the principal causes of preventable deaths. The Encuesta Nacional de Consumo de Drogas, Alcohol y Tabaco [National Survey of Drugs, Alcohol and Tobacco Use] (ENCODAT, 2016-2017) carried out in Mexico in the population aged 18 to 65, showed that there was a current prevalence of 20.1 million smokers (population about 14 million), of whom $9.8 \%$ were women $(3,602,000)$ and $31.3 \%$ were men $(10,206,000)$, which is a considerable figure considering the total population. But, in addition, when passive smokers are added to this, the consequences increase alarmingly (VillatoroVelázquez et al., 2017).

Despite decades of research on the relationship between tobacco, depression and anxiety, knowing that the presence of one increases the probability of the other, abstinence rates continue to be systematically lower for smokers with depression and/or anxiety than for smokers in the general population, highlighting the need to integrate components that address these problems (Mathew et al., 2017).

Therefore, since emotional comorbidity with tobacco impedes successful treatment, psychological interventions would have to be developed that enable the symptomatology to be approached simultaneously, thereby increasing the likelihood of abstinence (Martínez-Vispo et al., 2018).

The main elements dealing with comorbidity were incorporated by proposing effective, costefficient strategies which adapt to the needs of the Mexican healthcare system. Behavioral Activation (BA) is one of the most promising of these psychological intervention strategies (Jacobson et., 1996; Kanter et al., 2010; MacPherson et., 2010). In addition to being short and parsimonious, BA has a transdiagnostic vision which can focus on the dimensional elements in common in comorbidity instead of categories. This provides a common framework of intervention for smoking, depression and anxiety, which can be a promising complement to the standard abstinence strategies for smokers without depressive and anxiety symptoms (Aldi et al., 2018).

Studies have suggested that women tend to have less favorable long-term treatment results than men, and this has generally been attributed to negative emotional aspects (Chávez-Ayala et al., 2013; Godoy et al., 2016). One of the hypotheses that are consistent with this perspective is that people use tobacco as self-medication for managing negative symptoms of depression and anxiety (MorenoCoutiño et al., 2015).

Even though men generally smoke more than women (Villatoro-Velázquez et al., 2017), the risk of not quitting is higher among women when these negative emotional states are present, and that would be justification for treatment of women to include emotional aspects.

In this regard, Cooper et al. (2016) carried out a prospective study of 6811 smokers to find out whether depression predicted smoking cessation and whether it was influenced by gender. They concluded that, among women, depressive symptoms $(O R=0.63 ; 95 \% C I=0.49-0.81)$ and diagnosis of depression $(O R=0.46 ; 95 \% C I=0.34-0.63)$ negatively predicted abstinence, but not in men. These results were similar to Nakajima, \& Al'absi (2012) in women with depression $(O R=1.05 ; 95 \%$ $C I=1.01-1.10)$ and anxiety $(O R=1.12 ; 95 \% C I=1.02-1.22)$; to Peiper, \& Rodu (2013) $(O R=$ 1.05 ; $95 \% C I=1.02-1.34)$, in female smokers and depression; and Weinberger, \& McKee (2012). demonstrated gender differences in the relationship between negative affect and smoking behavior $(t=$ $2.26 ; p=.032 ; d=.68)$. 
Although this is well known, there is little in the literature on treatments addressing comorbid symptoms in smokers (Davoudi et al., 2017).

Behavioral Activation (BA) could contribute to the transdiagnostic approach of depression, anxiety and smoking. In the context of some studies, although oriented toward other mental healthrelated conditions, and albeit few, BA has been applied to smoking, and there is evidence of its contribution in this context to comorbid symptoms (Ekers et al., 2014; González-Roz et al., 2018; MacPherson et al., 2010; MacPherson et al., 2017; Martínez-Vispo et al., 2019).

Although much of the literature proceeds from high-income countries, experiences in Latin America are even scarcer, so evaluating the effectiveness of BA in the Mexican population would provide new data. BA is a treatment approach that can be applied to groups, and although there is not yet enough evidence that group therapy has better results than with individuals (Stead et al., 2017), it enables more people to be treated, which has many advantages.

In view of the above and in response to suggestions for further research in this regard, the objective of this study was to evaluate the effectiveness of BA on smoking in a group of women with depressive and anxiety symptoms receiving multicomponent treatment to quit smoking.

\section{Method}

\section{Participants}

The sample included 49 women who attended the National Institute of Respiratory Diseases (INER) Smoking Cessation Clinic in Mexico, 25 in the standard cognitive behavioral treatment and 24 in the BA group.

The selection was made by convenience sampling. Inclusion criteria were women $\geq 18$ years old, a depression score over 10 on the Beck Depression Inventory II (González et al., 2015), an anxiety score over 12 on the Beck Anxiety Inventory and signing the informed consent for voluntary participation. Exclusion criteria were a diagnosis of psychiatric disorders other than depression, anxiety or tobacco dependence according to the DSM-IV (Rodríguez et al., 2014), any medical impediment for regular session attendance, currently or in the last three months on medication and/or in psychological therapy to quit smoking, or for depression and/or anxiety management, and current consumption of illegal drugs.

\section{Sample Size calculation} over time:

The sample size was calculated using the mean difference formula to compare two groups

$$
\begin{aligned}
& \qquad \mathrm{N}=\frac{2(\mathrm{z} \alpha+\mathrm{z} \beta)^{2}(1+(\mathrm{n}-1) \rho)}{\mathrm{n}[(\mu 1-\mu 2) / \sigma]^{2}} \\
& \mathrm{~N}=\text { Total sample size. } \\
& \mathrm{Z} \alpha=.05 \text { (1.96) } \\
& \mathrm{Z} \beta=.842 \text { (statistical power } .8) \\
& \mu 1-\mu 2 / \sigma=.50 \text { (effect size) } \\
& \mathrm{n}=\text { minimum number of measurements over time (2) } \\
& \rho=.6 \text { (repeated measures correlation) }
\end{aligned}
$$




\section{Instruments}

The dependent variables were depression, anxiety, abstinence from use and behavioral activation, and were measured in pretreatment, posttreatment and face-to-face monitoring at one, three and six months with the following instruments:

\section{Beck-II Depression Inventory (BDI-II)}

The version adapted to the Mexican population by González et al. (2015) was used. Total scores range from 0-63 with the following cutoff points: 0-9, minimal depression; 10-16, mild; 17-28, moderate; and 29-63, severe. The scale has an internal consistency of $\alpha .87$ and a convergent and divergent validity $(r s>.70)$.

\section{Beck Anxiety Inventory (BAI)}

The version for the Mexican population by Robles, Varela, Jurado, \& Páez (2001) was used. The scale has an internal consistency of $\alpha .84$ and $\alpha .83$ and the test-retest reliability coefficient was $r$ $=.75$. Total scores range from 0-63 with the following cutoff points: 0-5, minimum; 6-15, mild; 16-30, moderate; and 31-63, severe.

\section{Behavioral Activation Scale for Depression (BADS)}

The Mexican version by Sánchez, Barraca, Mora, \& Reyes (2018) was used. The scale has an internal consistency of $\alpha .89$ and for each of the subscales: activation (7 items; $\alpha=.84$ ), avoidance/rumination ( 8 items; $\alpha=.84$ ), work/school deterioration (5 items; $\alpha=.77$ ) and social deterioration (5 items; $\alpha=.85$ ).

Fasgeström test.

The short Mexican version by Moreno-Coutiño, \& Villalobos-Gallegos (2017) was used. The scale has an internal consistency of .57 to .66. Levels set are low (0 to 3), moderate (4 to 6) and severe $(>6)$.

CO exhaled

A score of 6 or less on the Smokerlyzer® piCO monitor was considered current abstinence.

\section{Procedure}

The protocol was approved by the Comité Evaluador de Psicología de la Universidad Nacional Autónoma de México [Psychology Evaluation Committee of the National Autonomous University of Mexico], and by the Comité de Ética del Instituto Nacional de Enfermedades Respiratorias [Ethics Committee of the National Institute of Respiratory Diseases] (INER) in 2017 (C55-17). All participants signed their informed consent.

When the protocol had been approved by the Institute's ethics committee, the therapists collaborating in the project were trained, and the project was publicized to recruit patients. Each intervention group was assigned a therapist who had a Ph.D. and was trained in BA for the experimental group and in AIT for the standard group. The participants thus recruited were randomized into two groups by a researcher not involved in the study, using the WinPepi statistics program version 9. The control group received the standard intervention to stop smoking, consisting of cognitive behavioral therapy with emphasis on modifying thoughts to change behavior, in 10 twiceweekly 90-minute sessions + varenicline (see Table 1). 


\section{Table 1}

Standard Cognitive Behavioral Therapy for Smoking Cessation

\begin{tabular}{cll}
\hline Session & \multicolumn{1}{c}{ Name } & \multicolumn{1}{c}{ Points worked on } \\
\hline 1 & Introduction & $\begin{array}{l}\text { Smoking addiction theory, mechanisms of action of } \\
\text { nicotine, types of dependency and pharmacological } \\
\text { treatment. }\end{array}$ \\
\hline 2 & Analysis of reasons for smoking & Analysis of reasons for smoking. \\
\hline 3 & Abstinence & $\begin{array}{l}\text { Begin pharmacological treatment to quit smoking. } \\
\text { symptom withdrawal log passed out for homework. }\end{array}$ \\
\hline 5 & $\begin{array}{l}\text { Risk situations } \\
\text { Relaxation technique }\end{array}$ & $\begin{array}{l}\text { Analysis of risk situations, strategies for better coping and } \\
\text { a relaxation technique. }\end{array}$ \\
\hline 6 & $\begin{array}{l}\text { How smoking is harmful to } \\
\text { health and benefits of quitting }\end{array}$ & $\begin{array}{l}\text { Scientific information on how smoking is harmful to } \\
\text { health. }\end{array}$ \\
\hline 7 & Cognitive restructuring & Thoughts, emotions and behaviors related to abstinence. \\
& and advertising & Training in problem-solving. \\
\hline 8 & Nutrition and tobacco & $\begin{array}{l}\text { Scientific information on the metabolic changes associated } \\
\text { with abstinence and different choices in eating. }\end{array}$ \\
\hline 9 & Relapse prevention & Relapse and related situations. \\
\hline 10 & $\begin{array}{l}\text { Preparation for maintenance. } \\
\text { Closing }\end{array}$ & $\begin{array}{l}\text { Analysis of progress made in the treatment and the } \\
\text { strategies learned. }\end{array}$ \\
\hline
\end{tabular}

The experimental group received BA intervention, consisting of 10 twice-weekly 90-minute sessions, emphasizing planning and monitoring activities incompatible with smoking which serve as reinforcement and are valuable in the person's life + varenicline (see Table 2).

Table 2

Behavioral Activation Treatment for smoking

\begin{tabular}{cll}
\hline Session & \multicolumn{1}{c}{ Name } & \multicolumn{1}{c}{ Aspect to work } \\
\hline 1 & Introduction & $\begin{array}{l}\text { Functional analysis of behavior, according to the Behavioral } \\
\text { Activation Model by Martell et al. (2010). }\end{array}$ \\
\hline 2 & Smoking and emotions & $\begin{array}{l}\text { Analysis of the relationship between smoking and emotions. } \\
\text { Preparation for withdrawal. }\end{array}$ \\
\hline 3 & $\begin{array}{l}\text { Situations of risk and } \\
\text { behavioral activation }\end{array}$ & $\begin{array}{l}\text { Analysis of risk situations and programming of activities } \\
\text { incompatible with smoking. }\end{array}$ \\
\hline 4 & $\begin{array}{l}\text { Behavioral activation as an } \\
\text { action plan }\end{array}$ & $\begin{array}{l}\text { Monitoring of scheduled activities and planning new } \\
\text { activities. }\end{array}$ \\
\hline 5 & $\begin{array}{l}\text { Behavioral activation as an } \\
\text { action plan }\end{array}$ & $\begin{array}{l}\text { Monitoring of scheduled activities and planning new } \\
\text { activities. }\end{array}$ \\
\hline 6 & $\begin{array}{l}\text { Behavioral activation as an } \\
\text { action plan }\end{array}$ & $\begin{array}{l}\text { Monitoring of scheduled activities and planning new } \\
\text { activities. }\end{array}$ \\
\hline 8 & $\begin{array}{l}\text { Behavioral activation as an } \\
\text { action plan }\end{array}$ & $\begin{array}{l}\text { Monitoring of scheduled activities and planning new } \\
\text { activities. }\end{array}$ \\
\hline 8 & $\begin{array}{l}\text { Behavioral activation as an } \\
\text { action plan }\end{array}$ & $\begin{array}{l}\text { Monitoring of scheduled activities and planning new } \\
\text { activities. }\end{array}$ \\
\hline
\end{tabular}




\begin{tabular}{lll}
\hline 9 & $\begin{array}{l}\text { Behavioral activation as an } \\
\text { action plan }\end{array}$ & $\begin{array}{l}\text { Monitoring of scheduled activities and planning new } \\
\text { activities. }\end{array}$ \\
\hline 10 & $\begin{array}{l}\text { Relapse prevention and end } \\
\text { of therapy. }\end{array}$ & $\begin{array}{l}\text { Future risk situations } \\
\text { Action plans. }\end{array}$ \\
\hline
\end{tabular}

The treatment was applied by therapists with a Ph.D. trained in each approach using the Sansores et al, (1998) for the standard treatment, and the BA intervention adapted to smoking by Sánchez, Barraca, Mora, \& Reyes (2020).

During the admission assessment, in a semi-structured interview, participants were given information related to smoking, and completed depression, anxiety and behavioral activation measures. After about a one-month waiting period, the participants began the smoking cessation program according to the group assigned to them.

The varenicline dose in both groups was one $.5 \mathrm{mg}$ tablet in the morning for three days, from the fourth to the seventh day, one .5-mg tablet twice a day (morning and night), and from the eighth day to three months, $1 \mathrm{mg}$ twice a day (morning and night), supervised by a clinician who did not participate in the study, and the participant selection process was from August 2017 to December 2018 (see Figure 1).

\section{Figure 1}

\section{Participant selection process}

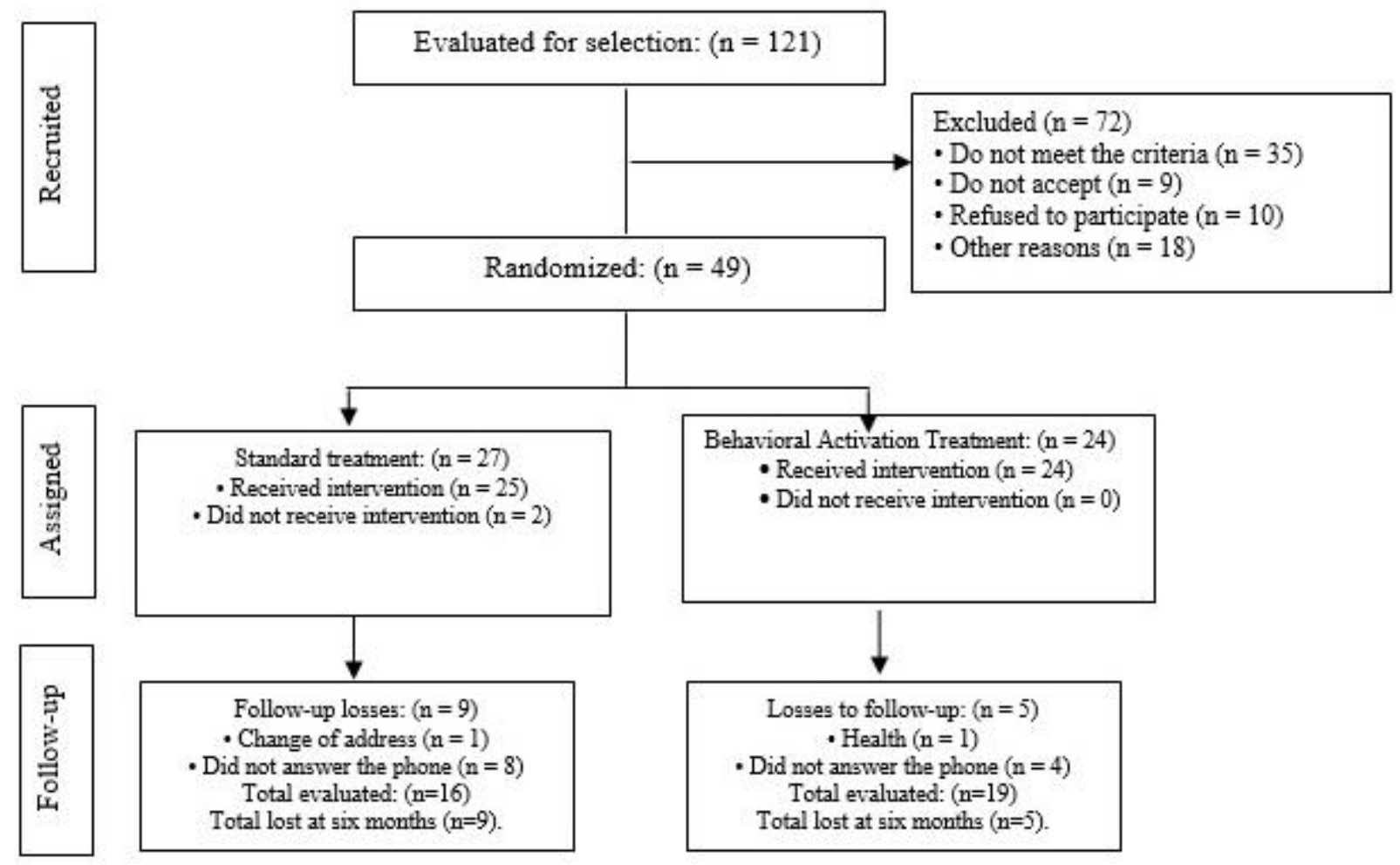

\section{Data Analysis}

For primary analyses, the group abstinence prevalence rates were compared using two types of analyses. The first was a Project-by-Project Analysis (PBP) with a Bivariate Logistic Regression 
Model to predict abstinence based on the type of treatment, with $P$-value less than $.05(p<.05)$, using the WinPepi statistics program version 9. Only those who completed the intervention and attended the follow-up at one, three or six months were included. The second was Intention-to-Treat Analysis (ITT), which included all the patients who were initially assigned to the groups. For the ITT, the Kaplan-Meier non-parametric method was used to assess the probability of withdrawal and compare by treatment. Log Rank was used to verify whether the change in withdrawal was due to the type of treatment, with significance level less than .05 $(p<.05)$, using the Statistical Package for Social Sciences, version 25.

For the secondary analyses, the Student's $t$-test for independent samples was used to compare the BAI, BDI and BADS pretreatment averages between the treatment groups.

Finally, the Bivariate Repeated Measures Analysis was used to assess the change from pretreatment to follow-up at six months, in the BDI, BAI, and BADS scores in the group that received BA. The Bonferroni adjustment was used to find any differences between measurements.

\section{Results}

\section{Baseline clinical characteristics}

Of the 49 participants who started, only 40 (81.6\%) accepted varenicline as a smoking cessation drug. Of these 40, 17 were in the BA group and 23 in the standard treatment group. Those who started pharmacological treatment completed three months on varenicline. This was verified during each follow-up session.

Secondly, a Student's $t$-test for independent samples was used and the homogeneity between groups was determined in pretreatment (see Table 3).

\section{Table 3}

Difference in the mean at baseline and clinical characteristics between the BA and standard treatment groups

\begin{tabular}{|c|c|c|c|c|c|c|c|c|}
\hline & \multicolumn{2}{|c|}{ MinimumMaximum } & $\begin{array}{l}\text { StD Group } \\
\quad(n=25) \\
\overline{\mathrm{x}}(\mathrm{SD})\end{array}$ & $\begin{array}{c}\text { BC } \\
\text { Group } \\
(n=24) \\
\overline{\mathrm{x}}(\mathrm{SD})\end{array}$ & $\begin{array}{c}\text { Student's } \\
t\end{array}$ & $d f$ & $p$ & $d$ \\
\hline Age & 29 & 69 & $47.92(10.39)$ & $51.58(11.59)$ & -1.116 & 47 & .250 & .39 \\
\hline Dependence & 0 & 10 & $4.76(2.78)$ & $5.71(2.49)$ & -1.253 & 47 & .216 & .35 \\
\hline $\begin{array}{c}\text { Years } \\
\text { Smoking }\end{array}$ & 1 & 50 & $28.32(11.06)$ & $33.71(11.36)$ & -1.681 & 47 & .099 & .48 \\
\hline $\begin{array}{l}\text { Cigarettes } \\
\text { per day }\end{array}$ & 5 & 40 & $13.64(7.67)$ & $12(7.48)$ & .757 & 47 & .453 & .21 \\
\hline $\begin{array}{l}\text { Attempts to } \\
\text { quit smoking }\end{array}$ & .00 & 6.00 & $1.16(.65)$ & $1.29(.72)$ & -.429 & 47 & .670 & .18 \\
\hline $\begin{array}{l}\text { Exhaled CO } \\
\text { pretreatment }\end{array}$ & 4 & 50 & $17.12(11.45)$ & $15.96(6.98)$ & .426 & 47 & .672 & .12 \\
\hline BDI & 9 & 33 & $19.20(6.38)$ & $19.96(5.20)$ & -.455 & 47 & .651 & .13 \\
\hline BAI & 3 & 54 & $21.76(7.99)$ & $23.75(12.92)$ & -651 & 47 & .518 & .18 \\
\hline BADS & 16 & 155 & $84.04(24.65)$ & $82.13(25.09)$ & .269 & 47 & .789 & .07 \\
\hline
\end{tabular}

Note: $\mathrm{StD}=$ Standard Treatment; $\mathrm{BA}=$ Behavioral Activation; $\overline{\mathrm{x}}=$ mean; $\mathrm{SD}=$ Standard deviation 


\section{Estimation of the group abstinence rate by ITT and PBP}

The relationship between the type of treatment and the occurrence of abstinence was calculated by Log Rank Chi-square. Of the 49 participants, 59.2\% were abstinent at the six-month follow-up, the majority of whom were in the group that received BA treatment $(66.7 \%)$, while most of those who were still smoking at the six-month follow-up were those who had received the standard treatment $(52 \%)$.

The Log Rank test showed that treatment type influenced the occurrence of withdrawal $\left(\chi^{2}=\right.$ 5.300; $p=.021)$, which lasted longer in the behavioral activation group $(\overline{\mathrm{x}}=180)$ than in the standard treatment group $(\overline{\mathrm{x}}=152)$, effect size $(\mathrm{r}=.67)$.

Results of the PBP showed that in the post-treatment measurement, the group that received BA had a higher probability of abstinence than the standard treatment group (OR of 16 [95\% CI 4.1$63, p<.001]$ ). The same occurred at one month (OR of 26 [95\% CI 6-118, $p<.001]$ ) and at three months of follow-up (OR of 7 [95\% CI 1.4-34, $p=.018]$ ). However, the effect at six months lost statistical value (OR 4.3 [95\% CI 0.32-57, $p=.27]$ ).

When the effect of treatment was measured with covariates such as age, depression and anxiety history, and nicotine dependence level, the same effect was observed for the BA group at the end of treatment (OR of 21 [95\% CI $6.3-68, p<.001]$ ), at one-month (OR 34 [95\% CI 9-133, $p<$ $.001]$ ) and three-month follow-up (OR 9.6 [95\% CI 2-45, $p=.004]$ ), but at six months, the OR also lost statistical significance (OR 5.4 [95\% CI 0.45-66, $p=.18]$ ).

\section{Secondary variables}

The Student's $t$-test for independent samples was used to evaluate the between-group differences in the BDI, BAI and BADS scores from the pretreatment to the six-month follow-up, showing that there was only a difference in the BDI scores at six months $(t=3.60 ; p=.003 ; d=1.64)$ and in the BADS at three months $(t=-2.418 ; p=.025 ; d=.42)$, but not in the rest of the measurements. The averages indicated that the standard group had higher BDI scores $(\overline{\mathrm{x}}=14.25)$ and lower BADS scores at six months $(\overline{\mathrm{x}}=81.83)$, than the BA group, $(\overline{\mathrm{x}}=7.42)$ and $(\overline{\mathrm{x}}=99.75)$, respectively.

The Student's $t$-test for independent samples was used to find out whether there was a difference in these scores between those who achieved abstinence at six months (59.2\%) and those who did not $(40.8 \%)$. The data indicated a difference only in BDI scores at six months $(t=-2.89 ; p=$ $.012 ; d=.58)$, in BAI at six months $(t=-3.25 ; p=.006 ; d=.41)$, and on the BADS at three months $\left(t=2.10 ; p=.048_{s} d=.61\right)$, but not in the rest of the measurements. In addition, those who achieved abstinence had lower scores on the BDI $(\overline{\mathrm{x}}=5.75)$ and BAI at six months $(\overline{\mathrm{x}}=6.25)$, and higher on the BADS $(\overline{\mathrm{x}}=102.77)$, than those who did not stop smoking, whose average was $(\overline{\mathrm{x}}=12.50),(\overline{\mathrm{x}}=$ 19) and $(\overline{\mathrm{x}}=83.44)$ respectively.

Since the BA group had lower BDI scores and higher BADS scores at six months, the change in these variables from pretreatment to six months was evaluated, using the Linear Model of Repeated Measures. All the variables fulfilled the assumption of homogeneity of variance $(p>.05)$. The Fisher value indicated the difference and reduction in BDI averages from pretreatment to the six-month follow-up $(\mathrm{F}=10.126 \mathrm{~b} ; p=.005)$. According to the $\mathrm{Eta}^{2}, 85.6 \%$ of BDI scores depended on treatment.

The Bonferroni Test (BSD) found differences between pretreatment and posttreatment (BSD $=8.364 ; p=.034)$, pretreatment and follow-up at one month $(\mathrm{BSD}=-10.273 ; p=.012)$, pretreatment 
and the third month of follow-up (BSD $=-7.63 ; p=.032$ ), and pretreatment and follow-up at six months $(\mathrm{BSD}=-11.091 ; p=.000)$. The decreasing trend in BDI scores was linear $(\mathrm{F}=30.16 ; p=$ $.000)$ with reduction in averages.

The BAI average scores indicate a reduction and a difference between measurements $(\mathrm{F}=$ 6.606; $p=.016$ ). As in the BDI, the Eta ${ }^{2}$ shows that $79.1 \%$ of the response of the variable depends on treatment. The only difference found was between the pretreatment and the one-month follow-up $(\mathrm{BSD}=13.455 ; p=.039)$ and the trend shows a linear reduction in scores $(\mathrm{F}=8.93 ; p=.014)$.

Finally, no significant differences in the BADS means $(\mathrm{F}=3.83 ; p=.059)$ were observed from the beginning of treatment to the six-month follow-up, although there was a trend of linear increase in the scores $(\mathrm{F}=5.763 ; p=.037)$.

Summarizing, the data show that BA therapy is effective for the treatment of women who attend smoking cessation treatment and is even comparable to standard treatment and has a higher abstinence rate and lower percentage of loss at six months, compared to the standard group. As secondary results, it was observed that those who stopped smoking showed lower scores on the BDI and BAI, and higher on the BADS than those who did not quit smoking. Those who received the BA treatment showed the best results.

\section{Discussion}

The objective of this study was to evaluate the effectiveness of behavioral activation on smoking in a group of women smokers with depressive and anxiety symptoms receiving multicomponent treatment to stop smoking. The four main findings were: First, BA with varenicline was more effective in terms of withdrawal outcomes up to six months than standard treatment with varenicline, according to the ITT, and comparable according to the PBP. Second, the presence of depressive symptoms decreased significantly up to the six-month follow-up in the BA group. Third, participants who achieved the most days of continuous withdrawal at each measurement time, had fewer depressive symptoms than those with fewer days of continuous withdrawal at that point, and fourth, BDI-II scores decreased at six months, while BADS scores increased, and this change was greater among those who had quit smoking.

In general, the findings of this study indicate that either BA as a single strategy or as a component of standard treatment could be useful for treating women with depression and anxiety for smoking in Mexico, because it resulted in higher probability of abstinence from point prevalence, lower dropout and more days of continuous abstinence from smoking at six-month follow-up.

The results expand the evidence from previous studies of BA treatment in smokers with depressive symptoms in comorbidity with anxiety symptoms (Hopko et al., 2016; Leventhal, y Zvolensky, 2015; Reynolds et al., 2011; Soleimani et al., 2015). Even though BA was not developed for smoking treatment per se, it can be a critical addition to treatment planning for cigarette smokers with concomitant depressive and anxiety symptoms.

It even agrees with Martínez-Vispo et al. (2018), who found that the results of their systematic review suggested that BA can help improve substance use abstinence and depressive symptoms, but that further research is needed to support its effectiveness.

This study also agrees with the systematic review carried out by Patnode et al. (2015), in which behavioral interventions combined with medication to stop smoking improved tobacco cessation rates in the general adult population up to $82 \%$ compared to minimal intervention or the usual intervention ( $R R, 1,82$ [IC, 1.66 to 2.00]). In addition, Stead et al. (2016) conducted a systematic review to assess the effect of combining behavioral support and medication to aid smoking cessation, compared to a minimal intervention or usual care, and to identify whether there are different effects 
depending on characteristics of the treatment setting, intervention, population treated, or take-up of treatment, and concluded that combine pharmacotherapy and behavioral support increase smoking cessation $(R R, 3.88,95 \%$ [CI 3.35 to 4.50]), results similar to Rovina et al. (2009) (OR=0.573, 95\%, $C I=0.221-1.487)$.

In agreement with the results of this research, some studies have also concluded that BA significantly reduces comorbid symptoms between smoking and emotional symptoms (MacPherson et al., 2017), while on the contrary, other studies, such as Busch et al. (2017) and González-Roz et al. (2018), found no significant difference between BA and the standard treatment for smoking cessation. It even appeared that BA had better results for substance use than for depression compared to a control condition, so withdrawal after treatment or during the follow-up period may have an impact on depression symptoms and not be due to the treatment itself (Iudicello et al., 2010; Mathew et al., 2013).

This contradiction in results may be due to the difference in tobacco dependence and depression severity levels. While in previous studies it was moderate to severe, in this study, although dependence was moderate to severe, symptomatology was mild to severe.

Despite the differences in the results of research on BA, and although more research is required to expand the evidence on the effect of BA in the treatment of women for smoking addiction, the findings of this study suggest that it could benefit women who have concomitant depressive and anxiety symptoms. However, this is an initial approach that requires further evidence of its scope, and to generalize these results, the effect of BA on sustained abstinence would have to be evaluated without the use of smoking cessation medication, since varenicline could have affected the results.

According to Secades-Villa et al. (2015), depressive symptoms can increase the probability of a tenacious smoking habit and decrease the smoking cessation rate due to various mechanisms. The participants with depressive symptoms may be smoking to alleviate negative mood symptoms, and although it is possible that this may be happening given the preliminary research data, it is a point that would still have to be confirmed in this research.

Therefore, as BA makes it possible to address the variables that harm the success of a smoking cessation treatment, such as depression and anxiety symptoms, it may have a positive effect in the treatment, and be more advantageous than standard treatments, which would indirectly prevent relapse.

\section{Limitations}

Based on the preliminary results, the limitations of the study should be taken into account. The sample size is small and may not have sufficient statistical power. Different therapists should also be able to participate in both group conditions, so that the therapeutic style is not a variable influencing the results. Men with anxiety/depressive symptoms should be included in the sample as well to see if the results differ by sex. Furthermore, it is important for other clinical symptom verification measures to be used and not just self-report questionnaires. And finally, it should be possible to observe the effect of the intervention on participants who did not take any type of medication for smoking cessation or concomitant symptoms during the study.

\section{Conclusions}

Although more research is needed to support the effectiveness of BA in treating smoking and concomitant depressive and anxious symptoms, these findings showed promising data. Future studies are required to investigate the mechanisms of BA action that could not be elucidated here, as well as any possible moderating variables that may have an impact on the results of depression and anxiety. 


\section{Acknowledgments}

We would like to thank the participants in the study and the Consejo Nacional de Ciencia y Tecnología [National Council of Science and Technology] (CoNaCyT) (Mexico) for financial aid granted for $\mathrm{Ph} . \mathrm{D}$. studies of the first author of the study (CVU) 619204 and fellowship Registration Number 335986, and for funding, and to the research team at the Instituto Nacional de Enfermedades Respiratorias [National Institute of Respiratory Diseases (INER)].

\section{References}

Aldi, G., Bertoli, G., Ferraro, F., Pezzuto, A., \& Cosci, F. (2018). Efectividad de las intervenciones farmacológicas o psicológicas para dejar de fumar en fumadores con depresión mayor o síntomas depresivos: una revisión sistemática de la literatura. Abuso de Sustancias, 39, 289306. https://doi.org/10.1080/08897077.2018.1439802Busch et al. 2017

Busch, A., Tooley, E., Dunsiger, S., Chattinllion, E., Fani, J., Pagoto, S., Khaler, Ch., \& Borrelli, B. (2017). Behavioral activation for smoking cessation and mood management following a cardiac event: results of a pilot randomized controlled trial. BMC Public Health, 17(323), 1-13. https://doi.org/10.1186/s12889-017-4250-7

Chávez-Ayala, R., Rivera-Rivera, L., Leyva-López, A., Sánchez-Estrada, M., \& Lazcano-Ponce, E. (2013). Orientación al rol de género y uso de tabaco y alcohol en jóvenes de Morelos, México. Salud Pública de Mexico, 55, 43-56.

Cooper, J., Borland, R., Mckee, Sh, Yong, H., \& Dugue, P. (2016). Depression motivates quit attempts but predicts relapse: Differential findings for gender from the International Tobacco Control Study. Addiction, 111(8), 1438-1447. https://doi.org/10.1111/add.13290

Davoudi, M., Omidi, A., Sehat, M., \& Sepehrmanesh, Z. (2017). Los efectos de la terapia de aceptación y compromiso sobre los síntomas de depresión y ansiedad comórbidos de los fumadores masculinos y el abandono del hábito de fumar: un ensayo controlado aleatorio. Adicción y Salud, 9(3), 129-138.

Ekers, D., Webster, L., Van Straten, A., Cuijpers, P., Richard, D., \& Gilbody, S. (2014). Behavioural activation for depression: An update of meta-analysis of effectiveness and subgroup analysis, PLOS ONE, 9(6), e100100. https://doi.org/10.1371/journal.pone.0100100

Godoy, R., Callejas, F., Tornero, A., Molina, A., Agustín, F., \& Tárraga, P. (2016). Factores asociados al éxito de los tratamientos del tabaquismo. Journal of Negative \& No Positive Results, 1(4), 131-137. https://doi.org/10.19230/jonnpr.2016.1.4.1028

González-Roz, A., Secades-Villa, R., \& Alonso-Pérez, F. (2018). Effects of combining contingency management with behavioral activation for smokers with depression. Addiction Research \& Theory, 27(2), 1-8. https://doi.org/10.1080/16066359.2018.1463371

González, D., Reséndiz, A., \& Reyes-Lagunes, I. (2015). Adaptation of the BDI-II in México. Salud Mental de México, 38(4), 237-244. https://doi.org/10.17711/SM.0185-3325.2015.033

Hopko, D., Lejuez, C., Ryba, M., Shorter, R., \& Bell, J. (2016). Support for the efficacy of behavioural activation in treating anxiety y in breast cancer patients, Clinical Psychologist, 20, 17-26. https://doi.org/10.1111/cp.12083

Iudicello, J., Woods, S., Vigil, O., Cobb, J., Cherner, M., \& Heaton, R. (2010). Longer term improvement in neurocognitive functioning and affective distress among methamphetamine users who achieve stable abstinence. Journal Clinical Experimental Neuropsychological, 32, 704-718. 
Jacobson, N., Dobson, K. Truax, P., Addis, M., Koerner, K., Gollan, J., Gortner, E., \& Prince, S. (1996). A component analysis of cognitive-behavioral treatment for depression. Journal of Consulting and Clinical Psychology, 64, 295-304.

Kanter, J., Santiago-Rivera, A., Rusch, L., Busch, A., \& West, P. (2010). Initial outcomes of a culturally adapted Behavioral Activation for Latinas diagnosed with depression at a community clinic. Behavior Modification, 34(2), 120-144. https://doi.org/10.1177/0145445509359682

Leventhal, A., \& Zvolensky, M. (2015). Anxiety, depression, and cigarette smoking: A transdiagnostic vulnerability framework to understanding emotion-smoking comorbidity. Psychological Bulletin, 141(1), 176-212. http://dx.doi.org/10.1037/bul0000003

MacPherson, L., Collado, A., Ninnemann, A., \& Hoffman, E. (2017). Development of a behavioral activation-based intervention for cigarette-smoking young adults. Cognitive and Behavioral Practice, 24(1), 101-114. http://dx.doi.org/10.1016/j.cbpra.2016.03.004

MacPherson, L., Tull, M., Matusiewicz, A., Rodman, S., Strong, D., Kahler, C., \& Lejuez, C. W. (2010). Randomized controlled trial of behavioral activation smoking cessation treatment for smokers with elevated depressive symptoms. Journal of Consulting and Clinical Psychology, 78(1), 55-61. https://doi.org/10.1037/a0017939

Martínez-Vispo, C., Martínez, Ú., López-Durán, A., Fernández del Río, E., \& Becoña, E. (2018). Effects of behavioural activation on substance use and depression: a systematic review. Substance Abuse Treatment, Prevention, and Policy, 13(1), 1-13. https://doi.org/10.1186/s13011-018-0173-2

Martínez-Vispo, C., López-Durán, A., \& Becoña, E. (2019). Activación conductual para el abandono del tabaco en una persona con depresión: un estudio de caso. Información Psicológica, 117, 7187. https://doi.org/dx.medra.org/10.14635/IPSIC.2019.117.2

Martell, C. R., Dimidjian, S., \& Herman-Dunn, R. (2010). Behavioral Activation for Depression: A Clinician's Guide. Guilford.

Mathew, A., Hogarth, L., Leventhal, A., Cook, J., \& Hitsman, B. (2017). Cigarette smoking and depression comorbidity: systematic review \& proposed theoretical model. Addiction, 112(3), 401-412. https://doi.org/10.1111/add.13604

Mathew, A., Robinson, J., Norton, P., Cinciripini, P., Brown, R., \& Blalock, J. (2013) Affective trajectories before and after a quit attempt among smokers with current depressive disorders. Nicotine \& Tobacco Research, 15, 1807-1815.

Moreno-Coutiño A, García-Anguiano F, Ruiz-Velasco S., \& Medina-Mora, M. (2015). Assessment of depressive symptoms in severe smokers with minimal-mild depressive symptomatology receiving pre-smoking abstinence for integrated treatment: a randomized clinical trial. Salud Mental de México, 38(6), 433-439.

Moreno-Coutiño, A., \& Villalobos-Gallegos, L. (2017). Psychometric Properties of the Fasgeström Test for Nicotine Dependence in a Sample of Mexican Smokers. Journal of Addictions Nursing, 28(1), 27-33. https://doi.org/10.1097/jan.0000000000000156

Nakajima, M., \& al'Absi, M. (2012). Predictors of Risk for Smoking Relapse in Men and Women: A Prospective Examination. Psychology of Addictive Behaviors, 26(3), 633-637. https://doi:10.1037/a0027280

Patnode, C. D., Henderson, J. T., Thompson, J. H., Senger, C. A., Fortmann, S. P., \& Whitlock, E. P. (2015). Behavioral counseling and pharmacotherapy interventions for tobacco cessation in aadults, including pregnant women: A review of reviews for the U.S. Preventive services task force. Annals of Internal Medicine, 163, 608-621. https://doi.org/10.7326/M15-0171

Peiper, N., \& Rodu, B. (2013). Evidence of sex differences in the relationship between current tobacco use and past-year serious psychological distress: 2005-2008 National Survey on Drug Use and 
Health. Social Psychiatry and Psychiatric Epidemiology, 48, 1261-1271. https://doi.org/10.1007/s00127-012-0644-0

Reynolds, E., MacPherson, L., Baruch, D., Tull, M., \& Lejuez, C. (2011). Integration of the brief behavioral activation treatment for depression (BATD) into a college orientation program: depression and alcohol outcomes. Journal Counseling Psychology, 58(4), 555-564. https://doi.org/10.1037/a0024634

Robles, R., Varela, R., Jurado, S., \& Páez, F. (2001). Versión mexicana del Inventario de Ansiedad de Beck: propiedades psicométricas. Revista Mexicana de Psicología, 18(2), 211-218.

Rodríguez, J., Senín, C., \& Perona, S. (2014). DSM-IV-TR al DSM-5: análisis de algunos cambios. International Journal of Clinical and Health Psychology, 14(3), 221-231.

Rovina, N., Nikoloutsou, L., Katsani, G., Dima, E., Fransis, K., Roussos, Ch., \& Gratziou, Ch. (2009). Effectiveness of pharmacotherapy and behavioral interventions for smoking cessation in actual clinical practice. Therapeutic Advances in Respiratory Disease, 3(6), 279-289. https://doi.org/10.1177/1753465809350653

Sánchez, J., Barraca, J., Mora, E., \& Reyes, M. (2018). Propiedades Psicométricas de la Escala de Activación Conductual para la Depresión (BADS) en una Muestra Mexicana. Clínica y Salud, 29(3), 151-155. http://dx.doi.org/10.5093/clysa2018a22

Sánchez, J., Barraca, J., Mora, J., \& Reyes, M. (2020). Proposal of a smoking cessation program treatment with based in Behavioral Activation. Análisis y Modificación de Conducta, 46(173), 3-22. http://dx.doi.org/10.33776/amc.v46i173-4.4675

Sansores-Martínez R, Córdoba-Ponce M, Espinosa-Martínez M, Herrera-Kiengelher L, RamírezVenegas A, Martínez-Rossier, L., \& VillalbaCalocall J. (1998). Evaluación del programa cognitivo-conductual para dejar de fumar del Instituto Nacional de Enfermedades Respiratorias. Revista del Instituto Nacional de Enfermedades Respiratorias, 11(1), 29-35.

Secades-Villa, R., Vallejo-Seco, G., García-Rodríguez, O., López-Níñez, C., Weidberg, S., \& González-Roz, A. (2015). Contingency management for cigarette smokers with depressive symptoms. Experimental and Clinical Psychopharmacology, 23(5), 351-360. https://doi.org/10.1037/pha0000044.

Soleimani, M., Mohammadkhani, P., Dolatshahi, B., Alizadeh, H., Overmann, K., \& Coolidge, F. (2015). A comparative study of group behavioral activation and cognitive therapy in reducing subsyndromal anxiety and depressive symptoms. Iranian Journal of Psychiatry, 10(2), 71-78.

Stead, L. F., Carroll, A. J., \& Lancaster, T. (2017). Group behaviour therapy programmes for smoking cessation. Cochrane Database of Systematic Reviews, 3, 1-94. https://doi.org/10.1002/14651858.CD001007.pub3

Stead, L. F., Koilpillai, P., Fanshawe, T., \& Lancaster, T. (2016). Combined pharmacotherapy and behavioural interventions for smoking cessation (Review). Cochrane Database of Systematic Reviews, 3, 1-98. https://doi.org/10.1002/14651858.CD008286.pub3

Villatoro-Velázquez, J. A., Reséndiz-Escobar, E., Mujica-Salazar, A., Bretón-Cirett, M., Cañas Martínez, V., Soto-Hernández, I., ..., \& Mendoza-Alvarado, L. (2017). Encuesta nacional de consumo de drogas, alcohol y tabaco 2016-2017: Reporte de tabaco. Secretaría de Salud. INSTITUTO NACIONAL DE PSIQUIATRÍA (inprf.gob.mx)

Weinberger, A., \& McKee, S. (2012). Gender Differences in Smoking Following an Implicit Mood Induction, Nicotine \& Tobacco Research, 14(5), 621-625. https://doi.org//10.1093/ntr/ntr198

World Health Organization. (2019). WHO report on the global tobacco epidemic, 2019: offer help to quit tobacco use. Health Promotion (who.int) 